Article

\title{
Outer Membrane Vesicles Derived from Klebsiella pneumoniae Influence the miRNA Expression Profile in Human Bronchial Epithelial BEAS-2B Cells
}

\author{
Federica Dell'Annunziata ${ }^{1,+}$, Concetta Paola Ilisso ${ }^{2,+}$, Carmela Dell'Aversana ${ }^{2}$ (D), \\ Giuseppe Greco ${ }^{1}$, Alessandra Coppola ${ }^{2}$, Francesca Martora ${ }^{1}$, Fabrizio Dal Piaz ${ }^{3}$, \\ Giuliana Donadio $^{3}$, Annarita Falanga ${ }^{4}$ (D), Marilena Galdiero ${ }^{1}$, Lucia Altucci ${ }^{2}$, \\ Massimiliano Galdiero ${ }^{1}$, Marina Porcelli ${ }^{2}$ (D), Veronica Folliero ${ }^{1, *}$ and Gianluigi Franci ${ }^{3, *(\mathbb{D})}$ \\ 1 Department of Experimental Medicine, University of Campania Luigi Vanvitelli, 80138 Naples, Italy; \\ federica.dellannunziata@unicampania.it (F.D.); petgiuseppegreco@gmail.com (G.G.); \\ francesca.martora@unicampania.it (F.M.); marilena.galdiero@unicampania.it (M.G.); \\ massimiliano.galdiero@unicampania.it (M.G.) \\ 2 Department of Precision Medicine, University of Campania Luigi Vanvitelli, 80138 Naples, Italy; \\ concettapaola.ilisso@unicampania.it (C.P.I.); carmela.dellaversana@cnr.it (C.D.); \\ alessandra.coppola@unicampania.it (A.C.); lucia.altucci@unicampania.it (L.A.); \\ marina.porcelli@unicampania.it (M.P.) \\ 3 Department of Medicine, Surgery and Dentistry Scuola Medica Salernitana, University of Salerno, \\ 84081 Salerno, Italy; fdalpiaz@unisa.it (F.D.P.); gdonadio@unisa.it (G.D.) \\ 4 Department of Agricultural Science, University of Naples Federico II, 80055 Naples, Italy; \\ annarita.falanga@unina.it \\ * Correspondence: veronica.folliero@unicampania.it (V.F.); gfranci@unisa.it (G.F.) \\ + These authors contributed equally to this work.
}

Received: 24 November 2020; Accepted: 11 December 2020; Published: 13 December 2020

\begin{abstract}
Klebsiella pneumoniae is an opportunistic pathogen that causes nosocomial and community-acquired infections. The spread of resistant strains of K. pneumoniae represents a growing threat to human health, due to the exhaustion of effective treatments. K. pneumoniae releases outer membrane vesicles (OMVs). OMVs are a vehicle for the transport of virulence factors to host cells, causing cell injury. Previous studies have shown changes of gene expression in human bronchial epithelial cells after treatment with K. pneumoniae OMVs. These variations in gene expression could be regulated through microRNAs (miRNAs), which participate in several biological mechanisms. Thereafter, miRNA expression profiles in human bronchial epithelial cells were evaluated during infection with standard and clinical K. pneumoniae strains. Microarray analysis and RT-qPCR identified the dysregulation of miR-223, hsa-miR-21, hsa-miR-25 and hsa-let-7g miRNA sequences. Target gene prediction revealed the essential role of these miRNAs in the regulation of host immune responses involving NF-kB (miR-223), TLR4 (hsa-miR-21), cytokine (hsa-miR-25) and IL-6 (hsa-let-7g miRNA) signalling pathways. The current study provides the first large scale expression profile of miRNAs from lung cells and predicted gene targets, following exposure to K. pneumoniae OMVs. Our results suggest the importance of OMVs in the inflammatory response.
\end{abstract}

Keywords: Klebsiella pneumoniae; outer membrane vesicles; miRNA; immune response; target genes

\section{Introduction}

K. pneumoniae is a significant opportunistic pathogen, mainly associated with hospital-acquired infections [1]. Studies have estimated that it causes $8 \%$ of all nosocomial bacterial infections in Europe 
and in the United States [2,3]. This bacterium is responsible for a broad spectrum of extraintestinal diseases such as sepsis, pneumonia, urinary tract, lungs, abdominal cavity and soft tissue infections [4]. K. pneumoniae has important virulence factors, such as lipopolysaccharides, a capsule, adhesins and siderophores, required for its mechanism of colonization, adherence, invasion and to enable the progression of infection [2,5]. In addition, hemolysins, tyrosine kinase, heat-stable enterotoxins and heat-labile exotoxins participate in the pathogenicity [6,7]. K. pneumoniae rapidly acquires antibiotic resistance mechanisms making the selection of the appropriate antibiotic treatment more challenging $[1,8]$. Carbapenem resistance appears to have the greatest impact on the effectiveness of the treatment. The European Centre for Disease Control and Prevention (ECDCP) assumed that $15.2 \%$ of K. pneumoniae strains are carbapenem resistant in Italy $[9,10]$. In this scenario, nosocomial K. pneumoniae infections reflect a 50\% mortality rate if untreated [11,12]. Given the clinical significance of this pathogen, a better understanding of other mechanisms of virulence is fundamental for designing new strategies to treat Klebsiella infections. It is well established that one of the characteristics of Gram-negative bacteria is their ability to form vesicles from the outer membrane, called outer-membrane vesicles (OMVs) [13-15]. OMVs are lipid bilayer spherical nanostructures with a diameter of 20-250 nm that are released into the host environment [16-18]. The surface of these vesicles is composed of lipopolysaccharide (LPS), phospholipids and outer membrane proteins [19,20]. The vesicular lumen, however, contains periplasmic and cytoplasmic components, including genetic material and virulence factors, such as invasion associated factors, toxins, and immune response modulators [21-23]. Thermolabile toxins and cytolysin have been identified in OMVs produced by Escherichia coli [24-26]. Haemolytic phospholipase $\mathrm{C}$ and alkaline phosphates have been detected in the OMVs of Pseudomonas aeruginosa [27-29]. Keenan et al. have found vacuolating cytotoxin A in the OMVs produced by Helicobacter pylori [18,30,31]. Since OMVs consist of toxins and several virulence determinants, it was postulated that the vesicles play a crucial role in bacteria-host interactions [32]. Previously, we demonstrated that OMVs of K. pneumoniae induce a strong inflammatory response in human bronchial epithelial cells (BEAS-2B) [13-15]. In these cells, OMVs strongly upregulate the expression of genes, encoding cytokines and chemokines [32]. In addition, the effect of the inflammatory cascade leads to pathogen clearance and host homeostasis [33-35]. Therefore, understanding cellular and molecular factors in response to the exposure of OMVs could be highly relevant for susceptibility to infection.

MicroRNAs (miRNAs) are small non-coding RNA molecules that are involved in the post-transcriptional regulation of gene expression [36,37]. These molecules are essential in different biological processes, such as development, proliferation, differentiation, cell death and disease [38]. In infected epithelial cells, downregulation of miRNAs increases the expression of cytokines, chemokines, adhesion factors and costimulatory molecules [39-42]. Little is known about the function of miRNAs in the human bronchial epithelial cells after OMV interaction. Therefore, the aim of our study was to evaluate the miRNA expression changes in BEAS-2 B treated with OMVs produced by standard and two clinical K. pneumoniae strains.

\section{Materials and Methods}

\subsection{Bacterial Strains and Cell Culture}

The strains used in the current study were K. pneumoniae reference strains (K. pneumoniae ATCC 10031), a multi-sensitive clinical strain of K. pneumoniae (MS K. pneumoniae) and carbapenemase-producing clinical strains of K. pneumoniae (KPC-producing K. pneumoniae). Identification and susceptibility patterns were detected by matrix assisted laser desorption ionization-time of flight mass spectrometry (Bruker Dal-tonics, Heidelberg, Germany) and Phoenix BD (Becton Dickinson, NJ, USA) systems, respectively, according to the manufacturer's instructions [43]. BEAS2B cells (ATCC CRL-9609) from human bronchial epithelial tract were used for the treatments. The cells were grown in Dulbecco's modified Eagle medium with $10 \%$ fetal bovine serum, 
$1 \%$ L-glutamine, $100 \mathrm{U} / \mathrm{mL}$ penicillin, $100 \mu \mathrm{g} / \mathrm{mL}$ streptomycin (Gibco BRL, Grand Island, NE, USA) at $37^{\circ} \mathrm{C}$ in $5 \% \mathrm{CO}_{2}$, according to the manufacturer's instructions.

\subsection{OMV Purification}

OMV purification was performed following the protocol used by Martora et al. with some slight modifications [13]. Briefly, three K. pneumoniae strains were grown in LB broth $\left(600 \mathrm{~mL}, 37^{\circ} \mathrm{C}\right.$, $180 \mathrm{rpm}$ ) to an $\mathrm{OD}_{600} \mathrm{~nm}$ value of 1 . The bacterial cells were decanted through centrifugation and supernatants were filtered at $0.45 \mu \mathrm{m}$ and $0.22 \mu \mathrm{m}$ (Millex-GS filters, Millipore, Darmstadt, Germany). The cell-free supernatants were centrifuged at $100,000 \times g$ for $2 \mathrm{~h}$ at $4{ }^{\circ} \mathrm{C}$ (centrifuge Optima XPN-100 Beckman Coulter and rotor 70Ti, Palo Alto, CA, USA). The pellets were washed in sterile PBS1X by ultracentrifugation and re-suspended in $200 \mu \mathrm{L}$ of PBS1X. The sterility of the OMVs was checked on LB agar plates. The purified OMVs were stored at $-20^{\circ} \mathrm{C}$ after dynamic light scattering (DLS) analysis.

\subsection{OMV Characterization}

The Z-average size (Z-ave) and polydispersity index (PDI) of the OMVs were defined by DLS. The vesicles were analysed using Malvern Zetasizer ZS90 (Malvern Panalytical Ltd., Malvern, UK). Z-ave defines the mean diameter of the vesicles in $\mathrm{nm}$ (d.nm) while PDI describes the particle size distribution. For DLS measurements, $40 \mu \mathrm{L}$ vesicle aliquots were transferred into disposable cuvettes and gently mixed to provide a homogeneous solution. Three independent aliquots were investigated, and three measurements were made for each. Data were analysed via Dispersion Technology Software (DTS) (V7.01) provided by Malvern Zetasizer Nano-ZS for particle sizing in solution. This software provided the Z-ave and PDI.PDI values lower than 0.05 indicate samples with highly monodisperse vesicular distribution. In contrast, PDI values greater than 0.2 denote samples with very wide vesicular distribution.

\subsection{Sodium Dodecyl Sulphate Poly-Acrylamide Gel Electrophoresis (SDS-PAGE)}

For protein quantization, vesicles were lysed with a $1 \%$ Triton $\mathrm{X}-100$ solution for $1 \mathrm{~h}$ at $4{ }^{\circ} \mathrm{C}$. The lysate was centrifuged for $30 \mathrm{~min}$ at $14,000 \times \mathrm{g}$. OMV proteins were quantified by a Bradford assay (HIMEDIA, Einhausen, Germany). Vesicle proteins from K. pneumoniae ATCC 10031, MS K. pneumoniae and KPC-producing K. pneumoniae were analysed by 10\% SDS-PAGE. The gel was stained with Coomassie brilliant blue (HIMEDIA, Einhausen, Germany). Proteins in the range of 30-40 kDa were investigated by MS and MS/MS analysis. The gel image was processed with the Adobe Photoshop program.

\subsection{Proteomic Analysis of OMVs and Protein Extraction}

The proteins from OMVs were identified using a classical gel-based proteomic approach. Briefly, the resulting bands were under the trypsin-catalysed in-gel digestion procedure. NanoUPLC-hrMS/MS analyses of the resulting peptide mixtures were performed on a Q-Exactive orbitrap mass spectrometer (Thermo Fisher Scientific, Waltham, MA, USA), coupled with a nanoUltimate300 UHPLC system (Thermo Fisher Scientific). Peptide separation was conducted on a capillary EASY-Spray PepMap column $(0.075 \mathrm{~mm} \times 50 \mathrm{~mm}, 2 \mu \mathrm{m}$, Thermo Fisher Scientific) using aqueous $0.1 \%$ formic acid (A) and $\mathrm{CH} 3 \mathrm{CN}$ containing $0.1 \%$ formic acid (B) as mobile phases and a linear gradient from $3 \%$ to $40 \%$ of $\mathrm{B}$ in $45 \mathrm{~min}$ and at a $300 \mathrm{~nL} \cdot \mathrm{min}^{-1}$ flow rate. Mass spectra were acquired over an $\mathrm{m} / \mathrm{z}$ range from 400 to 1800 . To achieve protein identification, MS and MS/MS data were analysed via Mascot software (v2.5, Matrix Science, Boston, MA, USA) analysis, using the non-redundant Data Bank UniprotKB/Swiss-Prot (Release 2020_03). Parameter sets were: (i) trypsin cleavage; (ii) carbamidomethylation of cysteine as a fixed modification and methionine oxidation as a variable modification; (iii) a maximum of two missed cleavages; and (iv) false discovery rate (FDR), calculated by searching the decoy database, $\leq 0.05$. 


\subsection{Cellular Exposure to OMVs}

BEAS $2 \mathrm{~B}$ cells $\left(5 \times 10^{5}\right.$ cells per well) were plated in a 6-well tissue culture plate at $37^{\circ} \mathrm{C}$ for $24 \mathrm{~h}$. After $24 \mathrm{~h}$, the culture medium was removed and OMVs from three strains $(5 \mu \mathrm{g} / \mathrm{mL})$ were added. As a negative control, the same volume of OMV solvent (PBS1X) was added to the cells. Six hours post exposure, cells were collected, and miRNA extractions were performed.

\subsection{RNA Extraction and miRNome Profiling}

Total RNA was purified with the PARIS mirVANA kit (Invitrogen, Carlsbad, CA, USA), according to the manufacturer's protocol. The RNA concentration was examined by NanoDrop 1000 spectrophotometer (Thermo Fisher Scientific). RNA reverse transcription was performed using the TaqMan MiRNA reverse transcription kit and Megaplex RT primers (Thermo Fisher Scientific). The expression of microRNAs in BEAB 2B cells was determined using the TaqMan Human MicroRNA array (Thermo Fisher Scientific). Briefly, the single-stranded cDNAs were amplified using the TaqMan Universal Master Mix PCR, and specific primers and probes present on the 384-well TaqMan miRNA array card (Thermo Fisher Scientific). The array was conducted on the Applied Biosystems Viia7 instrument (Life Technologies, Carlsbad, CA, USA) with the predefined thermal cycle conditions.

\subsection{Statistical Analyses}

To normalize the three miRNA data sets, the raw data of the cycle threshold $(\mathrm{Ct})$ were processed in $\mathrm{R}$, excluding the undetectable data, i.e., with a value of $\mathrm{C} t>34$. The $\Delta \mathrm{C} t$ values were obtained by subtracting the average of the $\mathrm{C} t$ values of the internal endogenous controls (RNU44, RNU48 and U6) from the $\mathrm{C} t$ value of the miRNA for the given sample, $\mathrm{C} t 0$. The $\Delta \Delta \mathrm{C} t$ was acquired by subtracting the $\Delta \mathrm{C} t$ of the sample from the sample control. The expression fold change was calculated by increasing the power of the negative $\Delta \Delta C t$ value by 2 . The relationship between $C t, \Delta C t, \Delta \Delta C t$ and fold change (FC) is given by the following equation: $\Delta \mathrm{C} t=\mathrm{C} t-\mathrm{C} t 0 ; \Delta \Delta \mathrm{C} t=\Delta \mathrm{C} t-\Delta \mathrm{C} t$ control; $\mathrm{FC}=2^{-\Delta \Delta \mathrm{C} t}$. We performed a t-test to identify the de-regulated miRNAs. A $p$-value $<=0.005$ indicated a significant difference. In particular, miRNAs were upregulated for $\operatorname{logFC} \geq 1.5$ while they were downregulated for $\log \mathrm{FC} \leq-0.5$. After normalising, a heat map of the data was generated using the $\mathrm{MeV}$ software in order to produce an informative visualisation through the $\mathrm{MeV}$ software (MeV v4.9.0, Shanghai, China). Complete linkage clustering with the Manhattan distance measurement method for the three datasets was used.

\subsection{Prediction and Function of miRNA Target Genes}

Three different databases, TargetScan (TargetScan v7.1, Cambridge, MA, USA), DIANA-microT-CDS (DIANA v5.0, Lamia, Greece) and miRTarBase (miRTarBase v8.0 beta, Hsinchu, Taiwan) were exploited to predict the target genes of the miRNA dataset. In agreement with the parameters set for each bioinformatic tool, the genes commonly predicted by all three algorithms were selected. The target genes were represented by the VennDiagram package in R. The Metascape software (Metascape v5.0, San Diego, CA, USA) was used for gene ontology (GO) enrichment analysis. The output of the analysis was associated with a $p<0.005$. In addition, the Metascape bioinformatics tool was used to establish the protein-protein interaction networks (PPI-Nets) and topological structure analysis was performed.

\subsection{0. miRNA Expression Analysis}

After total RNA extraction, miRNA sequences were converted into cDNA using the miScript II RT Kit (Qiagen), according to the manufacturer's protocol. Real-time quantitative PCR (RT-qPCR) was carried out with QuantiTectSYBR Green PCR Kit (Qiagen). The thermal protocol was as follows: $95^{\circ} \mathrm{C}$ for $15 \mathrm{~min}$ plus 40 cycles at $94^{\circ} \mathrm{C}$ for $30 \mathrm{~s}, 58^{\circ} \mathrm{C}$ for $34 \mathrm{~s}$ and $70^{\circ} \mathrm{C}$ for $34 \mathrm{~s}$ [44]. RT-qPCR data were the result of three independent experiments, each with three replicates and were represented as \pm s.e.m. 
RNA U6 small nuclear 6 pseudogene (RNU6-6P) was used for data normalization. The miRNA primers used in RT-qPCR are reported in Table 1.

Table 1. Qiagen GeneGlobe IDs of microRNA (miRNA) target sequences.

\begin{tabular}{cc}
\hline Target Name & GeneGlobe ID \\
\hline RNU6-6P & MS00033740 \\
\hline hsa-miR-223 & MS00009184 \\
\hline hsa-miR-21 & MS00009079 \\
\hline hsa-miR-25 & MS00003227 \\
\hline hsa-let-7g & MS00008337 \\
\hline
\end{tabular}

\section{Results}

\subsection{Characterization of K. pneumoniae-Derived OMVs}

In order to define the structural and functional characteristics of OMVs produced by K. pneumoniae, vesicles were purified from three different strains: K. pneumoniae ATCC 10031, MS K. pneumoniae (clinical isolate) and KPC-producing K. pneumoniae (clinical isolate). The strains were cultured to stationary phase and their OMVs were collected. To guarantee precise accuracy of the analyses, three independent purifications of the OMVs were performed for each strain. All vesicles were analysed in terms of diameter and size distribution, through DLS. DLS analysis showed that most OMVs of K. pneumoniae ATCC 10031 presented a diameter of $273.3 \pm 1.3 \mathrm{~nm}$ and were characterized by a slightly heterogeneous size distribution, confirmed by the polydispersity index of $0.329 \pm 0.021$. OMV vesicles from isolated clinical strains showed an increase in size and a greater heterogeneity of vesicular populations. The OMVs of MS K. pneumoniae predominately exhibited a diameter of $427.1 \pm 0.9 \mathrm{~nm}$ and the vesicle population showed a high heterogeneity, demonstrated by a polydispersity index of $0.417 \pm 0.017$. Similar results were obtained for OMVs produced by KPC-producing K. pneumoniae. The majority of these vesicles presented with a diameter of $483.3 \pm 1.7 \mathrm{~nm}$ and a polydispersity index of $0.333 \pm 0.132$, suggesting a heterogeneous population in size distribution (Table 2). All purified OMVs were quantified based on protein yield. Protein concentrations of $0.08 \pm 0.06 \mathrm{mg} / \mathrm{mL}, 0.14 \pm 0.03 \mathrm{mg} / \mathrm{mL}$ and $0.21 \pm 0.01 \mathrm{mg} / \mathrm{mL}$ had been generated by K. pneumoniae ATCC 10031, MS K. pneumoniae and KPC-producing K. pneumoniae, respectively, for $600 \mathrm{~mL}$ of LB culture (Table 3).

Table 2. Dynamic light scattering (DLS) analysis measurements of the Z-average size (Z-ave) and polydispersity index (PDI) of the outer membrane vesicles (OMVs).

\begin{tabular}{ccc}
\hline Bacterial Strain & Z-Ave (d.nm) & PDI \\
\hline K. pneumoniae ATCC 10031 & $273.3 \pm 1.3$ & $0.329 \pm 0.021$ \\
\hline MS K. pneumoniae & $427.1 \pm 0.9$ & $0.417 \pm 0.017$ \\
\hline KPC-producing K. pneumoniae & $483.3 \pm 1.7$ & $0.333 \pm 0.132$ \\
\hline
\end{tabular}

Table 3. Protein concentration of OMVs purified from different strains of K. pneumoniae.

\begin{tabular}{cc}
\hline Bacterial Strain & Protein Concentration $[\mathrm{mg} / \mathbf{m L}]$ \\
\hline K. pneumoniae ATCC 10031 & $0.08 \pm 0.06$ \\
\hline MS K. pneumoniae & $0.14 \pm 0.03$ \\
\hline KPC-producing K. pneumoniae & $0.21 \pm 0.01$ \\
\hline
\end{tabular}




\subsection{SDS-PAGE and LC-MS/MS Analysis of OMVs}

To evaluate the protein profile of the OMVs purified from K. pneumoniae ATCC 10031, MS K. pneumoniae and KPC-producing K. pneumoniae, $3.3 \mu \mathrm{g}$ of protein was subjected to $10 \%$ SDS-PAGE (Figure 1). Two major bands, in the range of 30-40 KDa, were detected in the OMVs from K. pneumoniae ATCC 10031, MS K. pneumoniae and KPC-producing K. pneumoniae, with a clear difference from the bacterial lysate protein profile, confirming the absence of bacterial contaminants. The main protein bands were digested with trypsin and mass spectrometry-based proteomic analysis was performed. Mass spectra analysis identified eight proteins common to all purified OMVs. The list of OMV proteins is reported in Table 4 in which identification name, function, molecular weight, and the total score values are indicated.

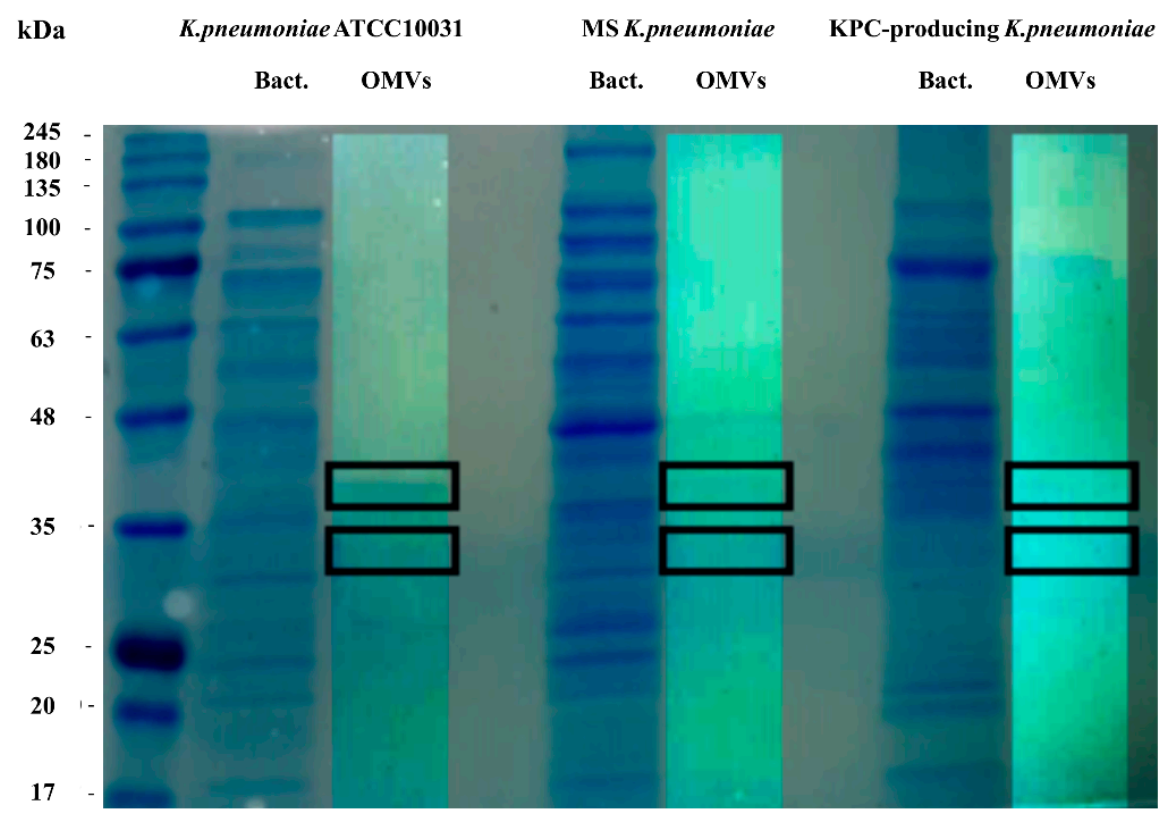

Figure 1. Coomassie-stained SDS-PAGE (10\%) protein profiles of K. pneumoniae ATCC 10031, MS K. pneumoniae and KPC-producing K. pneumoniae and relative OMVs. Molecular mass marker (MW) is expressed in kilodaltons $(\mathrm{kDa})$. The rectangles indicate the bands subjected to trypsin digestion and MS and MS/MS analysis.

Table 4. Protein profile commonly present in OMVs purified from different K. pneumoniae strains.

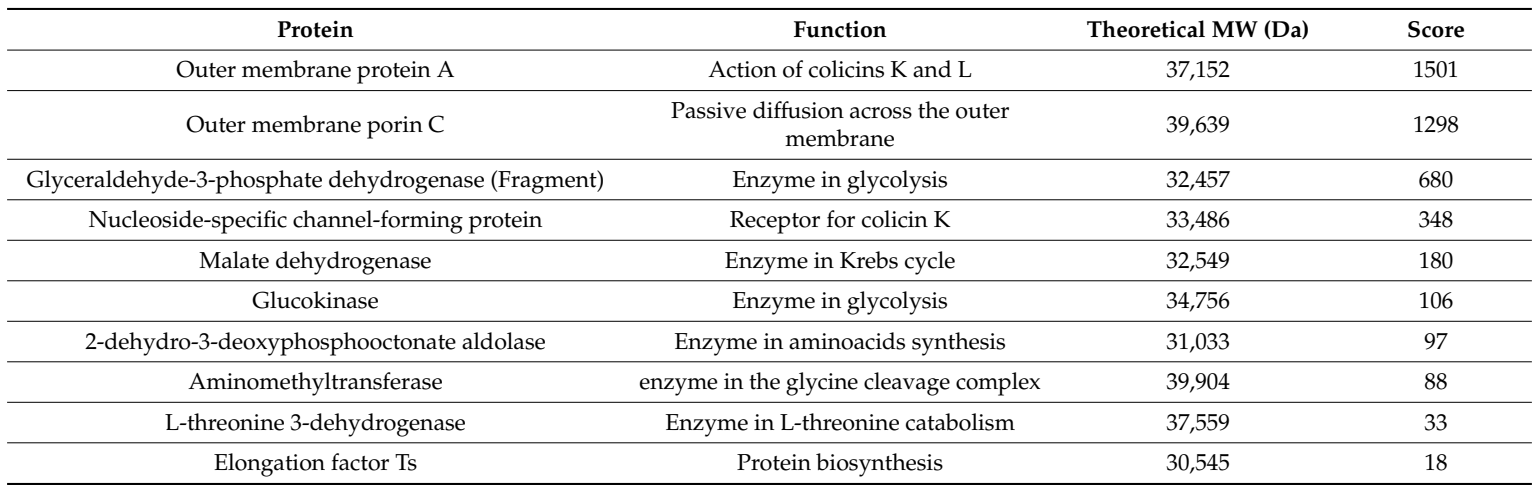

\subsection{K. pneumoniae-Derived OMVs Affect miRNA Expression Profile in BEAS-2B Cells}

The evaluation of the expression profiles of miRNAs was carried out after treating BEAS 2B cells with OMVs purified from K. pneumoniae ATCC 10031, MS K. pneumoniae and KPC-producing K. pneumoniae. Using the TaqMan miRNA Array CARD, we screened the expression level of 384 miRNA 
sequences [45]. Raw microarray data were filtered and analysed. To give an illustrative and informative depiction, the results are shown via heatmap, using MeV software (MultiExperiment Viewer) (Figure 2). Transcripts with upregulated expression are indicated in red, while downregulated transcripts are indicated in green. In particular, the analysis revealed 115 miRNA sequences that were differentially regulated in treated samples compared to untreated controls ( $p<0.05$; cut-off $>1.5$ or $<-0.5$ ). K. pneumoniae ATCC 10031 derived OMVs induced the upregulation of 81 and downregulation of 13 miRNAs. In cells treated with MS K. pneumoniae derived OMVs, 57 miRNAs were upregulated and 16 were downregulated. Incubation with KPC-producing K. pneumoniae derived OMVs altered the expression of 71 miRNAs (58 upregulated and 13 downregulated). The differential analysis of miRNome profiling in response to each of the three treatments was compared and shown in the Venn diagram in Figure 3. The dysregulated miRNAs were common to all the three samples and the individually dysregulated miRNAs in each sample were used for gene ontology, biological function, and pathway analysis.

\subsection{Functional Characterization of Target Genes}

Gene ontology enrichment analysis was performed using Metascape software. The DIANA gene, Target Scan gene and MirTarBase gene software were exploited to filter predicted data. There were 41 miRNAs that were upregulated and seven that were downregulated in all samples following exposure to OMVs from three different $K$. pneumoniae strains. Predicted target genes of upregulated miRNA sequences in BEAS-2B cells were significantly associated with "miRNA metabolic processes" (GO: 0010586), "cell division" (GO: 0051301), “developmental processes involved in reproduction" (GO: 0003006), "chromatin remodelling" (GO: 0006338) and "response to growth factor" (GO: 0070848) (Figure 4A). Target genes of seven downregulated miRNA sequences were involved in "regulation of acute inflammatory response" (GO: 0002673) (Figure 4B). All identified biological processes are closely related (Figure 4C). Our analysis also assessed the differences in expression of miRNA induced by K. pneumoniae ATCC 10031, MS K. pneumoniae and KPC-producing K. pneumoniae OMVs. After exposure with K. pneumoniae ATCC 10031, 19 and four miRNA sequences are upregulated and downregulated, respectively. Upregulated miRNA sequences were involved in "glandular epithelial cell development" (GO: 0002068), "DNA damage response, detection of DNA damage" (GO:0042769) and "positive regulation of apoptotic process" (GO: 0043065) (Figure 5A). The downregulated miRNAs were strongly associated with "cellular response to hormone stimulus" (GO: 0032870) (Figure 5B). The treatment with the MS strain upregulated and downregulated five different miRNA sequences in BEAS-2B cells. Five upregulated miRNA sequences were involved with the "adaptive immune system" (R-HSA-1280218) (Figure 5C) while the five downregulated miRNA sequences were related to the "cellular response to growth factor stimulus" (GO: 0071363), "regulation of neuron differentiation" (GO: 0045664) and "disease of signal transduction by growth factor receptors and second messengers "(R-HSA-5663202) (Figure 5D). The exposure to KPC-producing K. pneumoniae OMVs resulted in the upregulation and downregulation of five and three miRNA sequences, respectively. Upregulated sequences were involved in "FOXO-mediated transcription of cell death genes" (R-HSA-9614657), "positive regulation of organelle organization" (GO: 0010638) and "regulation of protein complex assembly" (GO: 0043254) (Figure 5E). Downregulated miRNA sequences were mainly associated with "columnar/cuboidal epithelial cell differentiation" (GO: 0002065) (Figure 5F). 


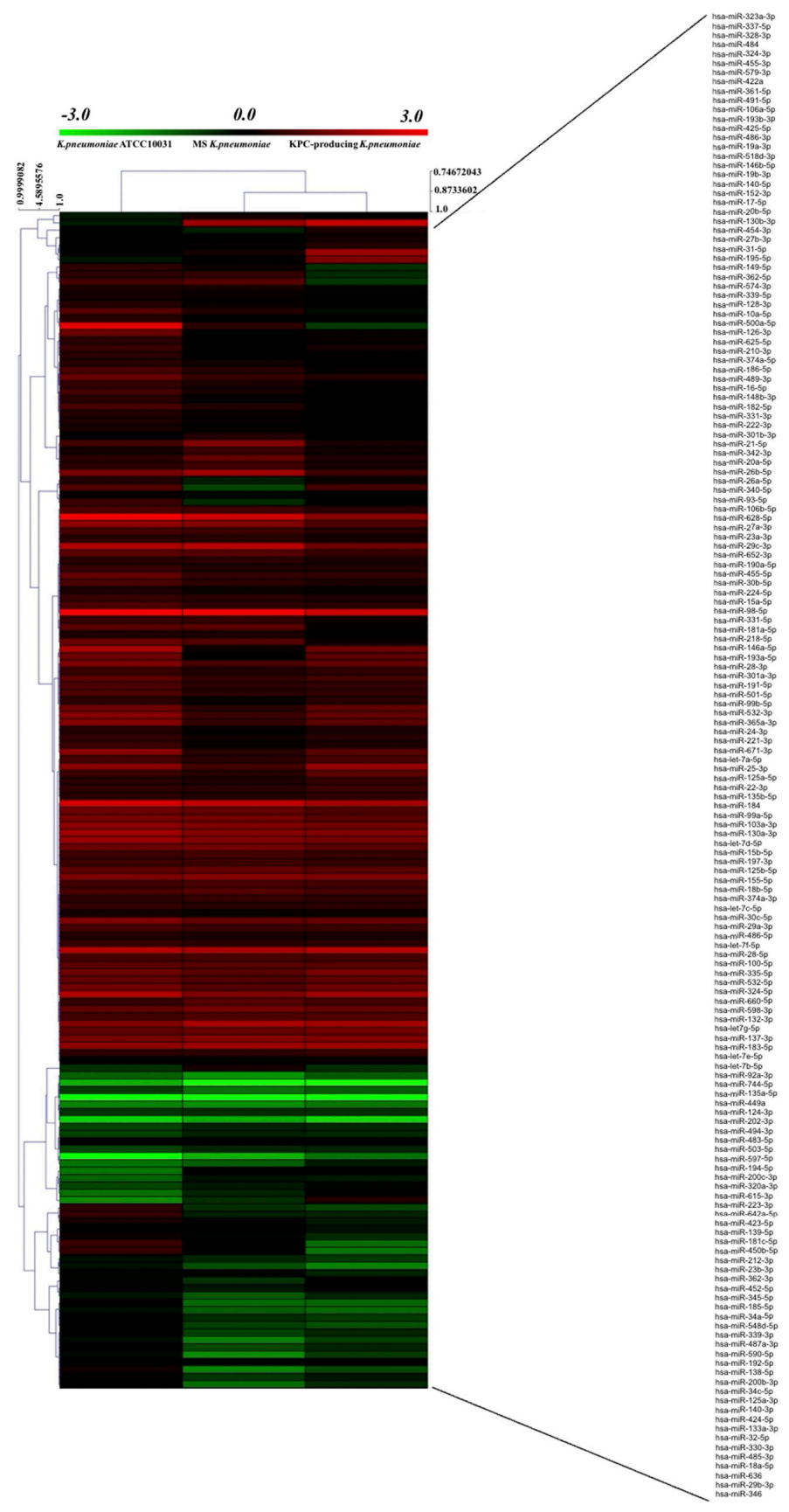

Figure 2. Heat map and hierarchical analysis of clusters. Heat map based on microarray results filtered and processed by bioinformatics analysis. Red indicates a greater expression than the control and green indicates a lower expression. 


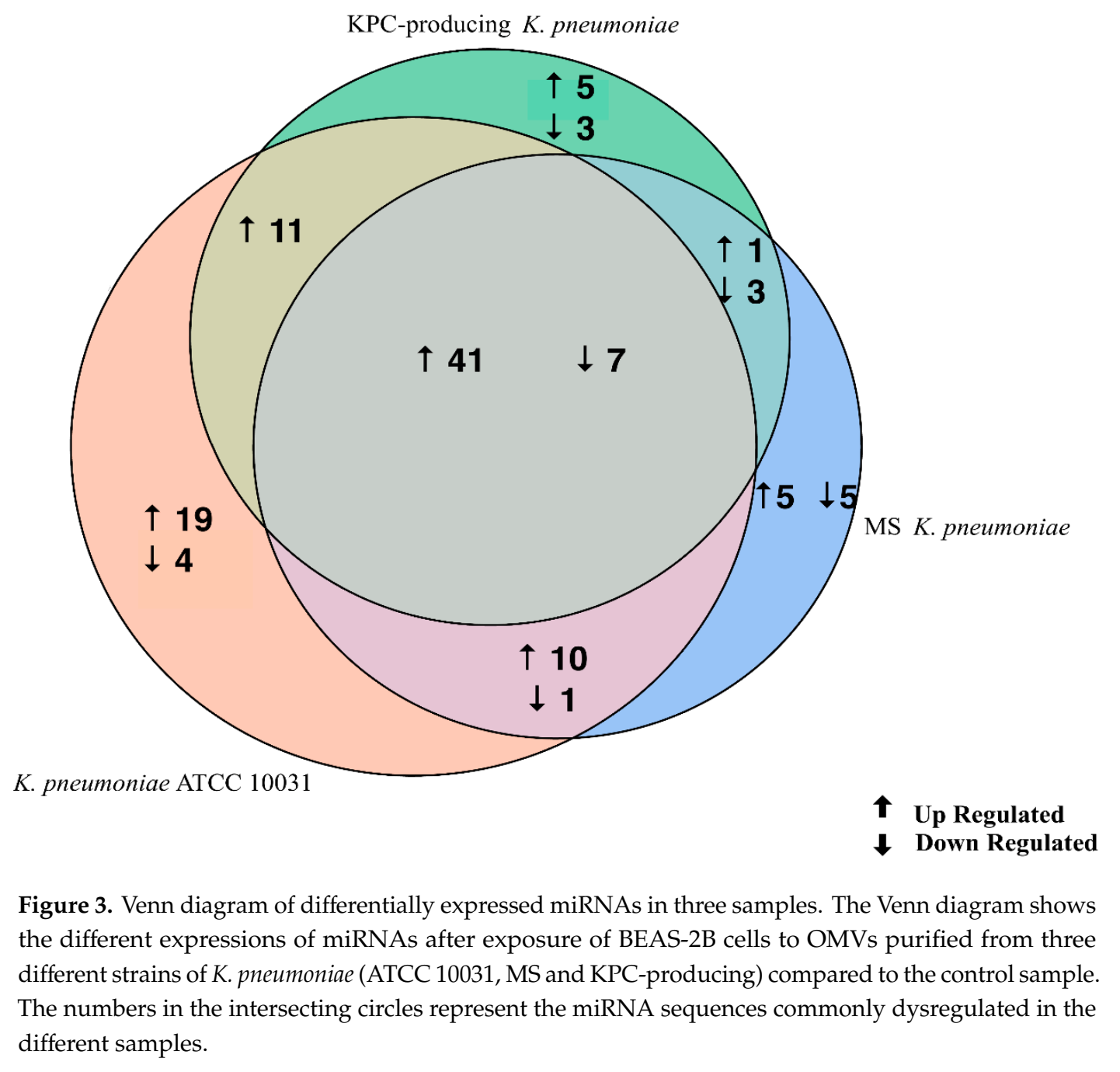




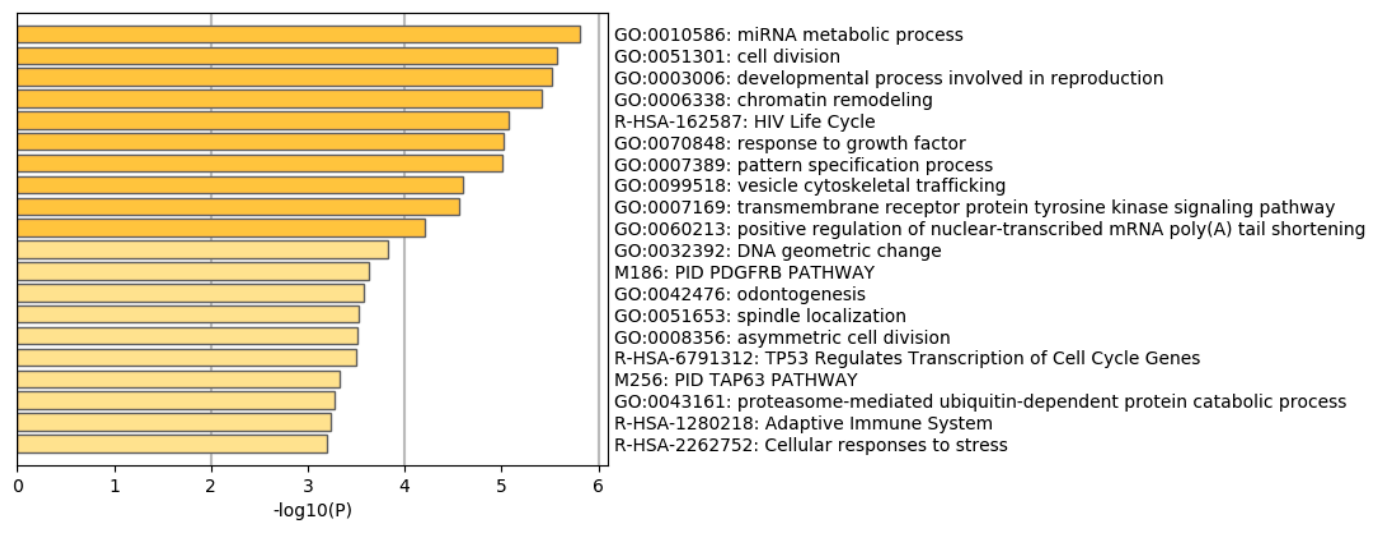

(A)

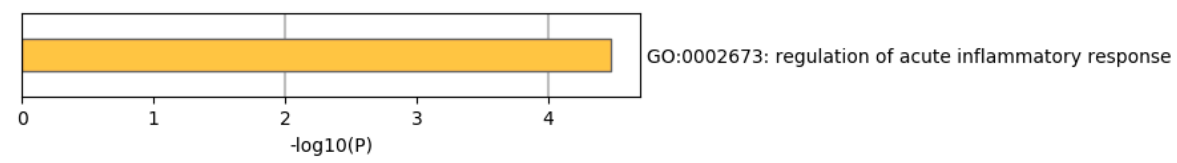

(B)

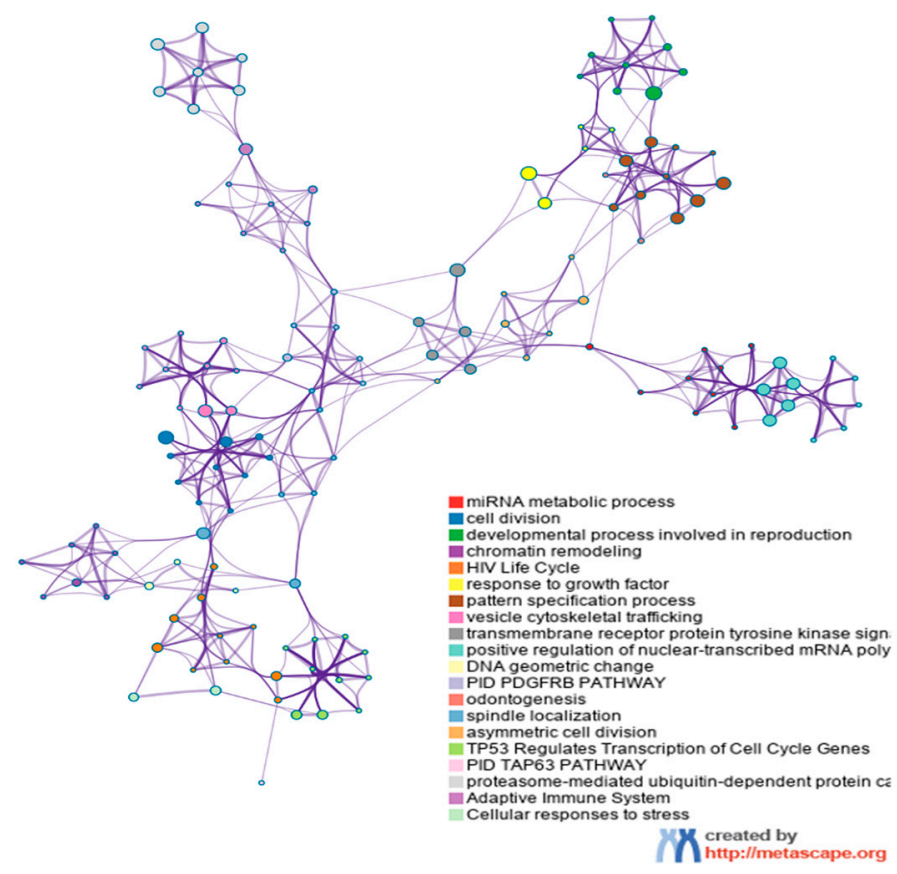

(C)

Figure 4. Analysis of the functional enrichment of target genes. (A,B) The main enrichment analysis clusters detected by Metascape of genes associated with upregulated miRNA after treatment with OMVs; (C) interaction network of the clusters detected by Metascape. The nodes of the same colour belong to the same cluster. Terms with a similarity score $>0.3$ are linked by an edge. The network is visualized with Cytoscape (v3.1.2) with a "force-directed" layout and edge bundled for clarity. 


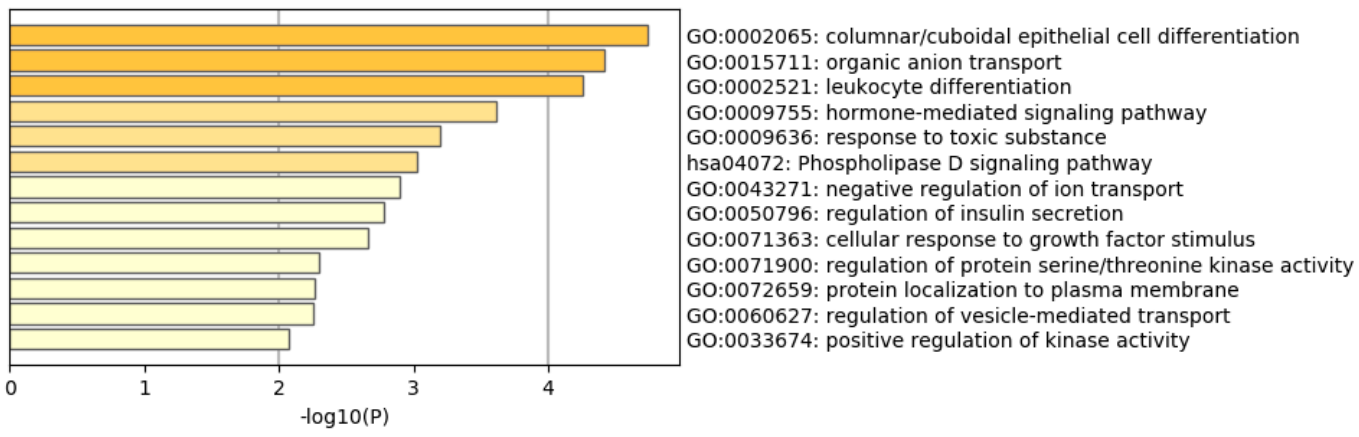

(A)

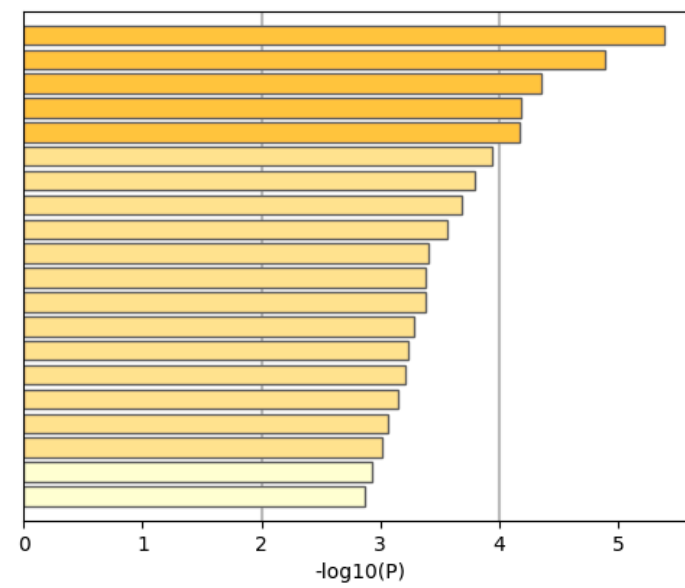

R-HSA-9614657: FOXO-mediated transcription of cell death genes GO:0010638: positive regulation of organelle organization GO:0043254: regulation of protein complex assembly GO:0009896: positive regulation of catabolic process GO:0070848: response to growth factor

GO:1903827: regulation of cellular protein localization GO:0051493: regulation of cytoskeleton organization GO:0006913: nucleocytoplasmic transport GO:0000910: cytokinesis

GO:0008285: negative regulation of cell proliferation GO:0051345: positive regulation of hydrolase activity GO:1901652: response to peptide GO:0018209: peptidyl-serine modification R-HSA-199991: Membrane Trafficking GO:0051651: maintenance of location in cell GO:0034504: protein localization to nucleus GO:0030099: myeloid cell differentiation GO:0034248: regulation of cellular amide metabolic process hsa04014: Ras signaling pathway GO:0006790: sulfur compound metabolic process

(B)

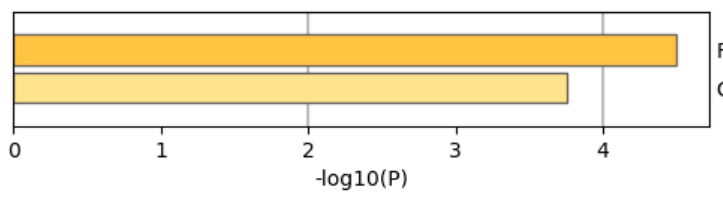

R-HSA-1280218: Adaptive Immune System GO:0050670: regulation of lymphocyte proliferation

(C)

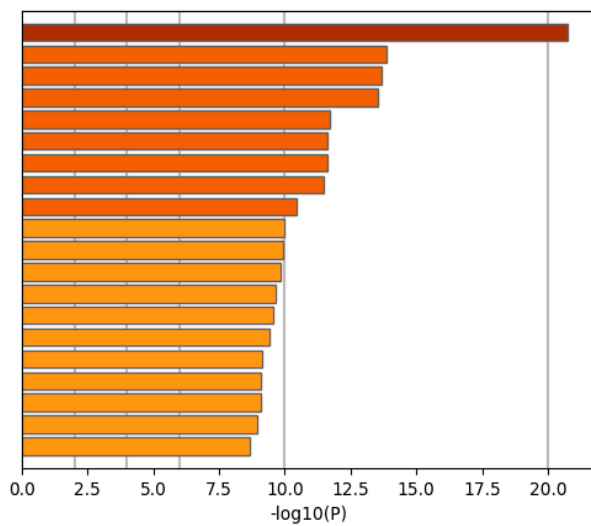

GO:0071363: cellular response to growth factor stimulus GO:0045664: regulation of neuron differentiation R-HSA-5663202: Diseases of signal transduction by growth factor receptors and second messengers GO:0032870: cellular response to hormone stimulus R-HSA-9614085: FOXO-mediated transcription GO:0007507: heart development hsa04151: PI3K-Akt signaling pathway GO:0060322: head development GO:0001568: blood vessel development GO:0010638: positive regulation of organelle organization GO:0090287: regulation of cellular response to growth factor stimulus Go:0016358: dendrite development R-HSA-9006925: Intracellular signaling by second messengers RO:0010942: positivaling by Receptor Tyrosine Kinases 0.0034330: cell junction organization hsa05206: MicroRNAs in cancer

GO:0031400: negative regulation of protein modification process M2579: ST DIFFERENTIATION PATHWAY IN PC12 CELLS

(D)

Figure 5. Cont. 


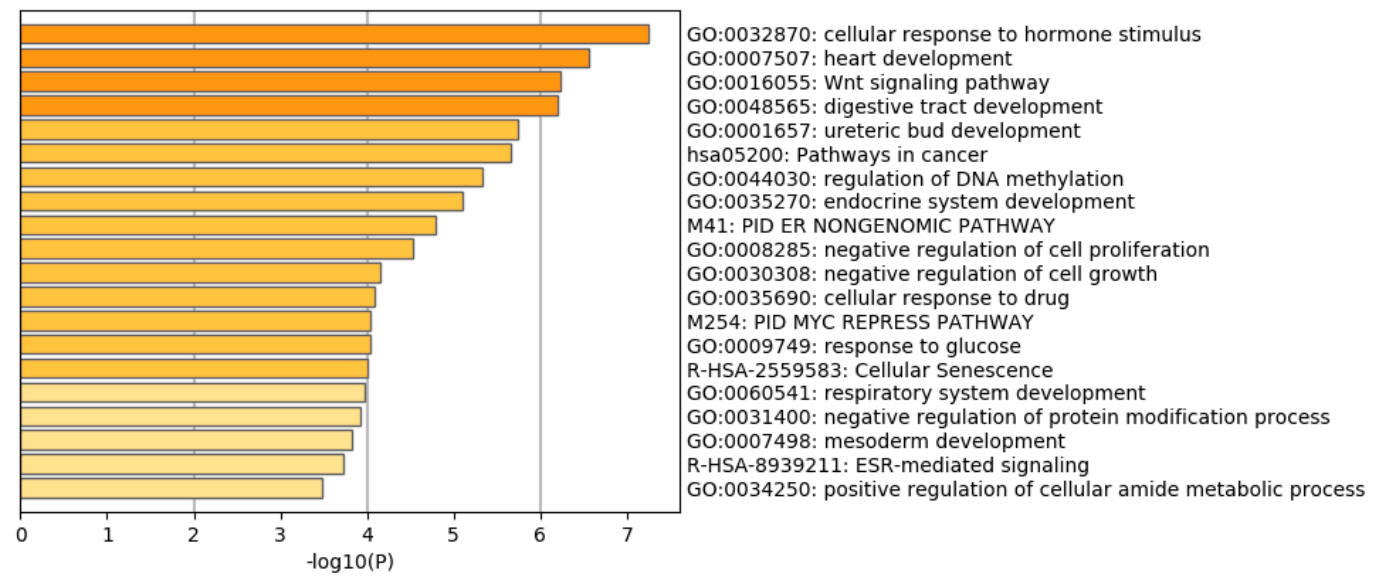

(E)

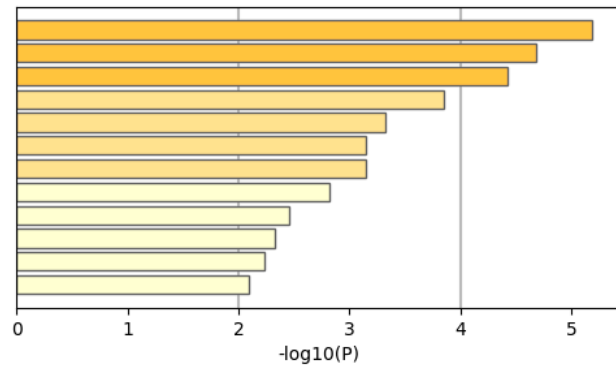

GO:0002068: glandular epithelial cell development

GO:0042769: DNA damage response, detection of DNA damage GO:0043065: positive regulation of apoptotic process hsa03320: PPAR signaling pathway

R-HSA-163685: Integration of energy metabolism

GO:0044257: cellular protein catabolic process

GO:0001838: embryonic epithelial tube formation

GO:0051301: cell division

GO:0007169: transmembrane receptor protein tyrosine kinase signaling pathway

GO:0015711: organic anion transport

hsa04144: Endocytosis

R-HSA-71387: Metabolism of carbohydrates

(F)

Figure 5. Gene prediction analysis. MiRNA sequences up and downregulated in the BEAS-2B sample exposed to OMVs of K. pneumoniae ATCC 10031 (A,B), MS K. pneumoniae (C,D) and KPC-producing K. pneumoniae (E,F).

\section{5. miRNAs Validation}

RT-qPCR was used to confirm the gene expression results obtained from microarray analysis. Four miRNAs (hsa-miR-223, hsa-miR-21, hsa-miR-25, hsa-let-7g) were selected for validation. The expression of the analysed miRNAs showed a good compliance with microarray data (Figure 6). These findings suggest that the microarray data were reliable, supported by similar fold changes. The expression levels in the miRNAs hsa-miR-223, hsa-miR-21 and hsa-let-7g were significantly higher in the treatment with KPC-producing K. pneumoniae OMVs. In contrast, the OMVs from MS strain induced higher expression levels than OMVs from ATCC 10031 strain. For hsa-miR-25, there were no significant variations in expression between treatment with OMVs derived from KPC-producing K. pneumoniae and MS strain. 
A

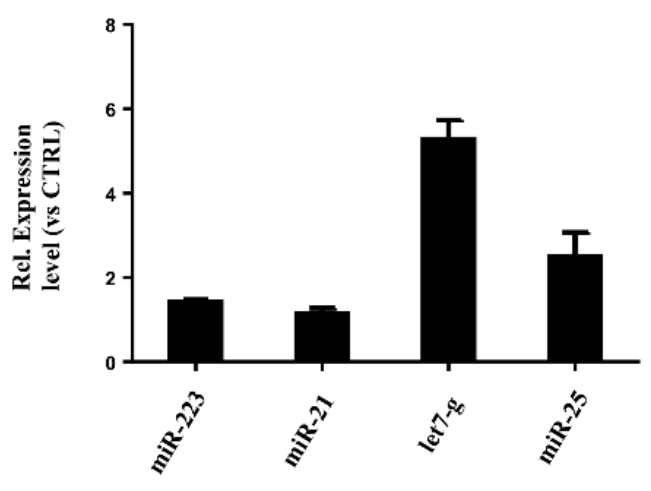

B

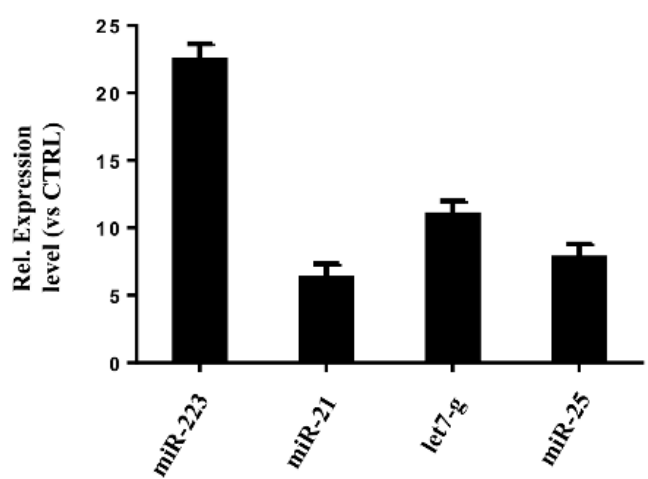

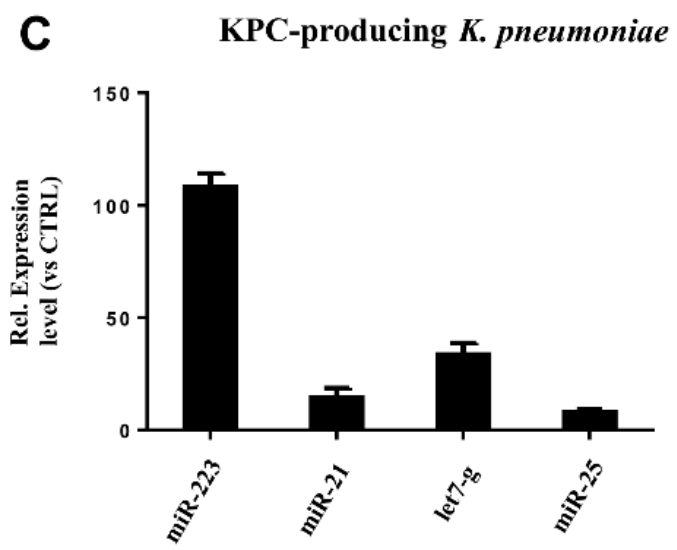

Figure 6. Validation of miRNA microarray data by real-time PCR. The expression levels of miR-21, miR-25, miR223, and let-7g were consistent with the miRNA microarray results after treatment with K. pneumoniae ATCC 10031 (A), MS K. pneumoniae (B) and KPC-producing K. pneumoniae (C).

\section{Discussion}

K. pneumoniae represents a worrying multi-resistant bacterium that causes nosocomial infections with high morbidity and mortality rates. A better understanding of the pathogenesis of K. pneumoniae infections is crucial. Several studies have shown that K. pneumoniae produces and secretes OMVs, which represent an important vehicle to transport many virulence effectors to host cells [46-48]. To the best of our knowledge, this was the first study reporting the differential expression of specific miRNA and their predicted target genes after exposure with OMVs purified from K. pneumoniae ATCC 10031, MS K. pneumoniae and KPC-producing K. pneumoniae. In this study, we highlight the different features of OMVs derived from three K. pneumoniae strains. The size of the vesicles was larger in clinical isolates (MS and KPC-producing) compared to the reference strain. These findings suggest that an increased load of virulence determinants could probably occur in the vesicles from clinical isolates. SDS-PAGE analysis of OMVs purified from K. pneumoniae ATCC 10031, MS K. pneumoniae and KPC-producing K. pneumoniae revealed two main protein bands in a range from 30 to $40 \mathrm{kDa}$. MS and MS/MS study identified these protein bands as outer membrane protein A, outer membrane porin C, glyceraldehyde-3-phosphate dehydrogenase, malate dehydrogenase, glucokinase, 2-dehydro-3-deoxyphosphooctonate aldolase, aminomethyltransferase, L-threonine 3-dehydrogenase and elongation factor Ts. The evident difference in the protein profile of the bacterial lysate suggests that the purification protocol exploited to isolate vesicles was successful in separating OMVs from bacterial contaminants.

Currently, no study has evaluated changes in cellular miRNoma after exposure to K. pneumoniae OMVs. In the present study, human bronchial epithelial cells were exposed to OMVs from K. pneumoniae ATCC 10031, MS K. pneumoniae and KPC-producing K. pneumoniae and cellular miRNoma was evaluated. Microarray analysis showed 115 differentially expressed miRNA sequences compared to the untreated 
sample. In particular, OMVs derived from K. pneumoniae ATCC 10031 caused upregulation and downregulation of 81 and 13 miRNAs, respectively. OMVs purified from MS K. pneumoniae changed the expression of 73 miRNAs (57 upregulated and 16 downregulated). Moreover, OMV treatment from KPC-producing K. pneumoniae induced the upregulation of 58 miRNAs and the downregulation of 13 miRNAs. Only 48 miRNA sequences were commonly dysregulated after treatment with the different vesicles. Of the latter, miR-223, hsa-miR-21, hsa-miR-25 and hsa-let-7g sequences were validated using RT-qPCR. MiR-223 has shown strong upregulation in the treatment with OMVs derived from KPC-producing K. pneumoniae. This miRNA has previously been shown to increase production of NF- $\mathrm{KB}$ mediated inflammatory cytokines [49]. In particular, miR-223 regulates IL-6 production, aiming to focus on STAT3 to improve TLR-mediated inflammatory responses [50]. Several studies have suggested that miR-223 is an important regulator of the innate immune system and response to bacterial stimulation. Levels of miR-223 were shown to gradually increase, doubling in $6 \mathrm{~h}$, then showing a three-fold increase after $24 \mathrm{~h}$ in Helicobacter pylori-infected THP-1 monocytes [51]. LPS is also able to regulate the expression of miR-223. Overexpression of miR-223 sequences occurs in LPS-activated macrophages [52]. Similar to the miR-223 sequence, hsa-miR-21 also acts in the control of the inflammatory response. This sequence was upregulated in all of the three treatments. By silencing the programmed cell death 4 (PDCD4) gene, hsa-miR-21 increased the production of the anti-inflammatory cytokine IL-10 and reduced NF-KB-induced inflammatory activity [53]. The high hsa-miR-21 expression was previously found in periodontal ligament tissues of patients with periodontitis. Porphyromonas gingivalis LPS exposure induced overexpression of miR-21 sequences in a murine macrophage cell line [54]. Moreover, in H. pylori-infected gastric epithelial cells, upregulation of MiR-21 occurred. [55]. Hsa-miR-25 is closely involved in the inflammatory response, by modulating changes in cytokine levels. This sequence can inhibit the expression of suppressor of cytokine signalling (SOCS) genes after cell treatment with K. pneumoniae OMVs [56]. Hsieh et al. showed that C57BL/6 mice receiving intraperitoneal injections of LPS from several bacterial species (E. coli, K. pneumoniae, P. aeruginosa, Salmonella enterica and Serratia marcescens) induced upregulated expression of miR-25 sequences in blood and epithelial cells [51]. Only hsa-let-7g showed significant downregulation, following treatment with OMVs purified from the three strains of K. pneumoniae. This miRNA sequence negatively regulates IL-6 expression, after LPS exposure [44]. S. enterica and its LPS component induced downregulation of let-7g in macrophages and epithelial cells, promoting the expression of cytokines [57]. These findings suggest that the downregulation of let-7g in BEAS-2B could be mostly attributed to the LPS component of OMVs.

Our present research study shows that the dysregulation of the selected miRNA suggests that OMVs derived from three K. pneumoniae strains represent potent inflammatory agents. In concordance with previously published studies, we confirmed that OMVs derived from K. pneumoniae contribute to the pathogenesis of infection in the host. Additionally, our findings improve the current understanding about the size and composition of OMVs, elucidating miRNA-mediated mechanisms related to K. pneumoniae infection. We are tempted to speculate about further investigations directed towards the development of OMVs as innovative vaccine strategies.

Author Contributions: Conceptualization, F.D. and V.F.; methodology, F.M., C.P.I. and G.D.; software, G.G.; validation, C.D., A.C. and C.P.I.; formal analysis, A.F.; investigation, F.D.P. and M.P.; resources, M.G. (Massimiliano Galdiero); data curation, M.G. (Marilena Galdiero); writing—original draft preparation; visualization, G.F.; supervision, L.A.; project administration, G.F.; funding acquisition, M.G. (Massimiliano Galdiero). All authors have read and agreed to the published version of the manuscript.

Funding: This research received no external funding.

Acknowledgments: The authors would like to thank the staff of U.O.C University Hospital of Campania "Luigi Vanvitelli" in Naples for their contributions. Many thanks to Andrea Scaloni and Chiara D'Ambrosio for contributing to the study of mass spectrometry. We sincerely thank Cameron Hay for improving the English spelling, grammar, and sentence structure of the manuscript. Moreover, we thank the Valere project of the University of Campania Luigi Vanvitelli for the support in publishing this article.

Conflicts of Interest: The authors declare no conflict of interest. 


\section{References}

1. Caneiras, C.; Lito, L.; Melo-Cristino, J.; Duarte, A. Community- and Hospital-Acquired Klebsiella pneumoniae Urinary Tract Infections in Portugal: Virulence and Antibiotic Resistance. Microorganisms 2019, 7, 138. [CrossRef] [PubMed]

2. Lee, C.R.; Lee, J.H.; Park, K.S.; Jeon, J.H.; Kim, Y.B.; Cha, C.J.; Jeong, B.C.; Lee, S.H. Antimicrobial Resistance of Hypervirulent Klebsiella pneumoniae: Epidemiology, Hypervirulence-Associated Determinants, and Resistance Mechanisms. Front. Cell. Infect. Microbiol. 2017, 7, 483. [CrossRef] [PubMed]

3. Podschun, R.; Ullmann, U. Klebsiella spp. as nosocomial pathogens: Epidemiology, taxonomy, typing methods, and pathogenicity factors. Clin. Microbiol. Rev. 1998, 11, 589-603. [CrossRef] [PubMed]

4. Bengoechea, J.A.; Sa Pessoa, J. Klebsiella pneumoniae infection biology: Living to counteract host defences. FEMS Microbiol. Rev. 2019, 43, 123-144. [CrossRef] [PubMed]

5. Paczosa, M.K.; Mecsas, J. Klebsiella pneumoniae: Going on the Offense with a Strong Defense. Microbiol. Mol. Biol. Rev. 2016, 80, 629-661. [CrossRef] [PubMed]

6. Lin, J.E.; Valentino, M.; Marszalowicz, G.; Magee, M.S.; Li, P.; Snook, A.E.; Stoecker, B.A.; Chang, C.; Waldman, S.A. Bacterial heat-stable enterotoxins: Translation of pathogenic peptides into novel targeted diagnostics and therapeutics. Toxins 2010, 2, 2028-2054. [CrossRef]

7. Wang, H.; Zhong, Z.; Luo, Y.; Cox, E.; Devriendt, B. Heat-Stable Enterotoxins of Enterotoxigenic Escherichia coli and Their Impact on Host Immunity. Toxins 2019, 11, 24. [CrossRef]

8. Buonocore, C.; Tedesco, P.; Vitale, G.A.; Esposito, F.P.; Giugliano, R.; Monti, M.C.; D’Auria, M.V.; de Pascale, D. Characterization of a New Mixture of Mono-Rhamnolipids Produced by Pseudomonas gessardii Isolated from Edmonson Point (Antarctica). Mar. Drugs 2020, 18, 269. [CrossRef]

9. Morrill, H.J.; Pogue, J.M.; Kaye, K.S.; LaPlante, K.L. Treatment Options for Carbapenem-Resistant Enterobacteriaceae Infections. Open Forum Infect. Dis. 2015, 2, ofv050. [CrossRef]

10. Nordmann, P.; Poirel, L. Epidemiology and Diagnostics of Carbapenem Resistance in Gram-negative Bacteria. Clin. Infect. Dis. 2019, 69, S521-S528. [CrossRef]

11. Qureshi,Z.A.; Syed, A.; Clarke, L.G.; Doi, Y.; Shields, R.K. Epidemiology and clinical outcomes of patients with carbapenem-resistant Klebsiella pneumoniae bacteriuria. Antimicrob. Agents Chemother. 2014, 58, 3100-3104. [CrossRef] [PubMed]

12. Geng, T.T.; Xu, X.; Huang, M. High-dose tigecycline for the treatment of nosocomial carbapenem-resistant Klebsiella pneumoniae bloodstream infections: A retrospective cohort study. Medicine 2018, 97, e9961. [CrossRef] [PubMed]

13. Martora, F.; Pinto, F.; Folliero, V.; Cammarota, M.; Dell'Annunziata, F.; Squillaci, G.; Galdiero, M.; Morana, A.; Schiraldi, C.; Giovane, A.; et al. Isolation, characterization and analysis of pro-inflammatory potential of Klebsiella pneumoniae outer membrane vesicles. Microb. Pathog. 2019, 136, 103719. [CrossRef] [PubMed]

14. Toyofuku, M.; Nomura, N.; Eberl, L. Types and origins of bacterial membrane vesicles. Nat. Rev. Microbiol. 2019, 17, 13-24. [CrossRef] [PubMed]

15. Wang, S.; Gao, J.; Wang, Z. Outer membrane vesicles for vaccination and targeted drug delivery. Wiley Interdiscip. Rev. Nanomed. Nanobiotechnol. 2019, 11, e1523. [CrossRef]

16. Kohl, P.; Zingl, F.G.; Eichmann, T.O.; Schild, S. Isolation of Outer Membrane Vesicles Including Their Quantitative and Qualitative Analyses. Methods Mol. Biol. 2018, 1839, 117-134. [CrossRef] [PubMed]

17. Schwechheimer, C.; Kuehn, M.J. Outer-membrane vesicles from Gram-negative bacteria: Biogenesis and functions. Nat. Rev. Microbiol. 2015, 13, 605-619. [CrossRef]

18. Zavan, L.; Bitto, N.J.; Johnston, E.L.; Greening, D.W.; Kaparakis-Liaskos, M. Helicobacter pylori Growth Stage Determines the Size, Protein Composition, and Preferential Cargo Packaging of Outer Membrane Vesicles. Proteomics 2019, 19, e1800209. [CrossRef]

19. Gerritzen, M.J.H.; Martens, D.E.; Wijffels, R.H.; van der Pol, L.; Stork, M. Bioengineering bacterial outer membrane vesicles as vaccine platform. Biotechnol. Adv. 2017, 35, 565-574. [CrossRef]

20. Lynch, J.B.; Schwartzman, J.A.; Bennett, B.D.; McAnulty, S.J.; Knop, M.; Nyholm, S.V.; Ruby, E.G. Ambient $\mathrm{pH}$ Alters the Protein Content of Outer Membrane Vesicles, Driving Host Development in a Beneficial Symbiosis. J. Bacteriol. 2019, 201, e00319-19. [CrossRef]

21. Ellis, T.N.; Kuehn, M.J. Virulence and immunomodulatory roles of bacterial outer membrane vesicles. Microbiol. Mol. Biol. Rev. 2010, 74, 81-94. [CrossRef] [PubMed] 
22. Guerrero-Mandujano, A.; Hernandez-Cortez, C.; Ibarra, J.A.; Castro-Escarpulli, G. The outer membrane vesicles: Secretion system type zero. Traffic 2017, 18, 425-432. [CrossRef] [PubMed]

23. Langlete, P.; Krabberod, A.K.; Winther-Larsen, H.C. Vesicles From Vibrio cholerae Contain AT-Rich DNA and Shorter mRNAs That Do Not Correlate With Their Protein Products. Front. Microbiol. 2019, 10, 2708. [CrossRef] [PubMed]

24. Bauwens, A.; Kunsmann, L.; Marejkova, M.; Zhang, W.; Karch, H.; Bielaszewska, M.; Mellmann, A. Intrahost milieu modulates production of outer membrane vesicles, vesicle-associated Shiga toxin 2a and cytotoxicity in Escherichia coli O157:H7 and O104:H4. Environ. Microbiol. Rep. 2017, 9, 626-634. [CrossRef]

25. Jan, A.T. Outer Membrane Vesicles (OMVs) of Gram-negative Bacteria: A Perspective Update. Front. Microbiol. 2017, 8, 1053. [CrossRef]

26. Li, M.; Zhou, H.; Yang, C.; Wu, Y.; Zhou, X.; Liu, H.; Wang, Y. Bacterial outer membrane vesicles as a platform for biomedical applications: An update. J. Control. Release 2020, 323, 253-268. [CrossRef]

27. Bomberger, J.M.; Maceachran, D.P.; Coutermarsh, B.A.; Ye, S.; O’Toole, G.A.; Stanton, B.A. Long-distance delivery of bacterial virulence factors by Pseudomonas aeruginosa outer membrane vesicles. PLoS Pathog. 2009, 5, e1000382. [CrossRef]

28. Cooke, A.C.; Nello, A.V.; Ernst, R.K.; Schertzer, J.W. Analysis of Pseudomonas aeruginosa biofilm membrane vesicles supports multiple mechanisms of biogenesis. PLoS ONE 2019, 14, e0212275. [CrossRef]

29. Koeppen, K.; Barnaby, R.; Jackson, A.A.; Gerber, S.A.; Hogan, D.A.; Stanton, B.A. Tobramycin reduces key virulence determinants in the proteome of Pseudomonas aeruginosa outer membrane vesicles. PLoS ONE 2019, 14, e0211290. [CrossRef]

30. Fiocca, R.; Necchi, V.; Sommi, P.; Ricci, V.; Telford, J.; Cover, T.L.; Solcia, E. Release of Helicobacter pylori vacuolating cytotoxin by both a specific secretion pathway and budding of outer membrane vesicles. Uptake of released toxin and vesicles by gastric epithelium. J. Pathol. 1999, 188, 220-226. [CrossRef]

31. Ronci, M.; Del Prete, S.; Puca, V.; Carradori, S.; Carginale, V.; Muraro, R.; Mincione, G.; Aceto, A.; Sisto, F.; Supuran, C.T.; et al. Identification and characterization of the alpha-CA in the outer membrane vesicles produced by Helicobacter pylori. J. Enzym. Inhib. Med. Chem. 2019, 34, 189-195. [CrossRef] [PubMed]

32. Cecil, J.D.; Sirisaengtaksin, N.; O’Brien-Simpson, N.M.; Krachler, A.M. Outer Membrane Vesicle-Host Cell Interactions. Microbiol. Spectr. 2019, 7, 201-214. [CrossRef]

33. Atkins, D.; Furuta, G.T. Mucosal immunology, eosinophilic esophagitis, and other intestinal inflammatory diseases. J. Allergy Clin. Immunol. 2010, 125, S255-S261. [CrossRef] [PubMed]

34. Chen, J.K.; Guo, M.K.; Bai, X.H.; Chen, L.Q.; Su, S.M.; Li, L.; Li, J.Q. Astragaloside IV ameliorates intermittent hypoxia-induced inflammatory dysfunction by suppressing MAPK/NF-kappaB signalling pathways in Beas-2B cells. Sleep Breath. 2020, 24, 1237-1245. [CrossRef] [PubMed]

35. Clark, H.R.; Powell, A.B.; Simmons, K.A.; Ayubi, T.; Kale, S.D. Endocytic Markers Associated with the Internalization and Processing of Aspergillus fumigatus Conidia by BEAS-2B Cells. mSphere 2019, 4. [CrossRef] [PubMed]

36. Giudice, A.; D’Arena, G.; Crispo, A.; Tecce, M.F.; Nocerino, F.; Grimaldi, M.; Rotondo, E.; D'Ursi, A.M.; Scrima, M.; Galdiero, M.; et al. Role of Viral miRNAs and Epigenetic Modifications in Epstein-Barr Virus-Associated Gastric Carcinogenesis. Oxid Med. Cell. Longev. 2016, 2016, 6021934. [CrossRef]

37. Powell, C.D.; Quain, D.E.; Smart, K.A. The Impact of Ageing on CHITIN Scars in Saccharomyces cerevisiae. Sci. World J. 2001, 1, 145. [CrossRef]

38. Mens, M.M.J.; Ghanbari, M. Cell Cycle Regulation of Stem Cells by MicroRNAs. Stem. Cell. Rev. Rep. 2018, 14, 309-322. [CrossRef]

39. Jung, N.; Schenten, V.; Bueb, J.L.; Tolle, F.; Brechard, S. miRNAs Regulate Cytokine Secretion Induced by Phosphorylated S100A8/A9 in Neutrophils. Int. J. Mol. Sci. 2019, 20, 5699. [CrossRef]

40. McCoy, C.E. The role of miRNAs in cytokine signaling. Front. Biosci. 2011, 16, 2161-2171. [CrossRef]

41. Nejad, C.; Stunden, H.J.; Gantier, M.P. A guide to miRNAs in inflammation and innate immune responses. FEBS J. 2018, 285, 3695-3716. [CrossRef] [PubMed]

42. Salvi, V.; Gianello, V.; Tiberio, L.; Sozzani, S.; Bosisio, D. Cytokine Targeting by miRNAs in Autoimmune Diseases. Front. Immunol. 2019, 10, 15. [CrossRef] [PubMed] 
43. Folliero, V.; Caputo, P.; Della Rocca, M.T.; Chianese, A.; Galdiero, M.; Iovene, M.R.; Hay, C.; Franci, G.; Galdiero, M. Prevalence and Antimicrobial Susceptibility Patterns of Bacterial Pathogens in Urinary Tract Infections in University Hospital of Campania "Luigi Vanvitelli" between 2017 and 2018. Antibiotics 2020, 9, 215. [CrossRef] [PubMed]

44. Huang, H.C.; Yu, H.R.; Hsu, T.Y.; Chen, I.L.; Huang, H.C.; Chang, J.C.; Yang, K.D. MicroRNA-142-3p and let-7g Negatively Regulates Augmented IL-6 Production in Neonatal Polymorphonuclear Leukocytes. Int. J. Biol. Sci. 2017, 13, 690-700. [CrossRef]

45. Ilisso, C.P.; Delle Cave, D.; Mosca, L.; Pagano, M.; Coppola, A.; Mele, L.; Caraglia, M.; Cacciapuoti, G.; Porcelli, M. S-Adenosylmethionine regulates apoptosis and autophagy in MCF-7 breast cancer cells through the modulation of specific microRNAs. Cancer Cell Int. 2018, 18, 197. [CrossRef]

46. Lee, J.C.; Lee, E.J.; Lee, J.H.; Jun, S.H.; Choi, C.W.; Kim, S.I.; Kang, S.S.; Hyun, S. Klebsiella pneumoniae secretes outer membrane vesicles that induce the innate immune response. FEMS Microbiol. Lett. 2012, 331, 17-24. [CrossRef]

47. Cahill, B.K.; Seeley, K.W.; Gutel, D.; Ellis, T.N. Klebsiella pneumoniae O antigen loss alters the outer membrane protein composition and the selective packaging of proteins into secreted outer membrane vesicles. Microbiol. Res. 2015, 180, 1-10. [CrossRef]

48. Turner, K.L.; Cahill, B.K.; Dilello, S.K.; Gutel, D.; Brunson, D.N.; Alberti, S.; Ellis, T.N. Porin Loss Impacts the Host Inflammatory Response to Outer Membrane Vesicles of Klebsiella pneumoniae. Antimicrob. Agents Chemother. 2015, 60, 1360-1369. [CrossRef]

49. Yuan, X.; Berg, N.; Lee, J.W.; Le, T.T.; Neudecker, V.; Jing, N.; Eltzschig, H. MicroRNA miR-223 as regulator of innate immunity. J. Leukoc. Biol. 2018, 104, 515-524. [CrossRef]

50. Wu, J.; Niu, P.; Zhao, Y.; Cheng, Y.; Chen, W.; Lin, L.; Lu, J.; Cheng, X.; Xu, Z. Impact of miR-223-3p and miR-2909 on inflammatory factors IL-6, IL-1ss, and TNF-alpha, and the TLR4/TLR2/NF-kappaB/STAT3 signaling pathway induced by lipopolysaccharide in human adipose stem cells. PLoS ONE 2019, 14, e0212063. [CrossRef]

51. Hsieh, C.H.; Rau, C.S.; Jeng, J.C.; Chen, Y.C.; Lu, T.H.; Wu, C.J.; Wu, Y.C.; Tzeng, S.L.; Yang, J.C.S. Whole blood-derived microRNA signatures in mice exposed to lipopolysaccharides. J. Biomed. Sci. 2012, 19, 69. [CrossRef] [PubMed]

52. Dang, C.P.; Leelahavanichkul, A. Over-expression of miR-223 induces M2 macrophage through glycolysis alteration and attenuates LPS-induced sepsis mouse model, the cell-based therapy in sepsis. PLOS ONE 2020, 15, e0236038. [CrossRef] [PubMed]

53. Ajuyah, P.; Hill, M.; Ahadi, A.; Lu, J.; Hutvagner, G.; Tran, N. MicroRNA (miRNA)-to-miRNA Regulation of Programmed Cell Death 4 (PDCD4). Mol. Cell. Biol. 2019, 39, e00086-19. [CrossRef]

54. Zhou, W.; Su, L.; Duan, X.; Chen, X.; Hays, A.; Upadhyayula, S.; Shivde, J.; Wang, H.; Li, Y.; Huang, D.; et al. MicroRNA-21 down-regulates inflammation and inhibits periodontitis. Mol. Immunol. 2018, 101, 608-614. [CrossRef] [PubMed]

55. Zhang, Z.; Li, Z.; Gao, C.; Chen, P.; Chen, J.; Liu, W.; Xiao, S.; Lu, H. miR-21 plays a pivotal role in gastric cancer pathogenesis and progression. Lab. Investig. 2008, 88, 1358-1366. [CrossRef] [PubMed]

56. Mei, Z.; Chen, S.; Chen, C.; Xiao, B.; Li, F.; Wang, Y.; Tao, Z. Interleukin-23 Facilitates Thyroid Cancer Cell Migration and Invasion by Inhibiting SOCS4 Expression via MicroRNA-25. PLoS ONE 2015, 10, e0139456. [CrossRef]

57. Schulte, L.N.; Eulalio, A.; Mollenkopf, A.J.; Reinhardt, R.; Vogel, J. Analysis of the host microRNA response to Salmonella uncovers the control of major cytokines by the let-7 family. EMBO J. 2011, 30, 1977-1989. [CrossRef]

Publisher's Note: MDPI stays neutral with regard to jurisdictional claims in published maps and institutional affiliations. 